\title{
Munc13-1 C1 Domain Activation Lowers the Energy Barrier for Synaptic Vesicle Fusion
}

\author{
Jayeeta Basu, ${ }^{1}$ Andrea Betz, ${ }^{2}$ Nils Brose,${ }^{2}$ and Christian Rosenmund ${ }^{1}$ \\ ${ }^{1}$ Departments of Neuroscience and Molecular and Human Genetics, Baylor College of Medicine, Houston, Texas 77030, and ${ }^{2}$ Max-Planck-Institute for \\ Experimental Medicine, Department of Molecular Neurobiology, D-37075 Göttingen, Germany
}

Synapses need to encode a wide dynamic range of action potential frequencies. Essential vesicle priming proteins of the Munc13 (mammalian Unc13) family play an important role in adapting vesicle supply to variable demand and thus influence short-term plasticity characteristics and synaptic function. Structure-function analyses of Munc13s have identified a "catalytic" C-terminal domain and several N-terminal modulatory domains, including a diacylglycerol/phorbol ester [ $4 \beta$-phorbol-12, 13-dibutyrate (PDBu)] binding C1 domain. Although still allowing basal priming, a Munc13-1 C1 domain mutation (H567K) prevents PDBu induced potentiation of evoked transmitter release, leads to strong depression during trains of synaptic activity, and causes perinatal lethality in mice. To understand the mechanism of $\mathrm{C} 1$ domain-mediated modulation of Munc13 function, we examined how PDBu increases neurotransmitter release. Analyses of osmotically induced release as well as $\mathrm{Ca}^{2+}$ triggered and spontaneous release showed that PDBu increases the vesicular release rate without affecting the size of the readily releasable vesicle pool, linking $\mathrm{C} 1$ domain activation to a lowering of the energy barrier for vesicle fusion. PDBu binding-deficient mutant Munc13-1 ${ }^{\mathrm{H} 567 \mathrm{~K}}$ synapses mirrored the vesicular release properties of PDBu-potentiated wild-type synapses, indicating that Munc13-1 ${ }^{\mathrm{H} 567 \mathrm{~K}}$ is a gain-of-function mutant, which conformationally mimics the PDBu-activated state of Munc13-1. We propose a PKC analogous two-state model of regulation of Munc13s, in which the basal state of Munc13s is disinhibited by $\mathrm{C} 1$ domain activation into a state of facilitated vesicle release, regardless of whether the release is spontaneous or action potential triggered.

Key words: exocytosis; presynaptic mechanisms; release probability; phorbol; patch clamp; neurotransmission

\section{Introduction}

Synaptic vesicle fusion with the presynaptic active zone membrane is the key step in neurotransmitter release. Before action potential-triggered fusion, vesicles need to dock to the active zone and become primed. Priming dramatically increases the propensity for vesicular release by lowering of the energy barrier for fusion. This enables the vesicles to efficiently use the action potential-induced $\mathrm{Ca}^{2+}$ transient for timed exocytosis. Only a fraction of synaptic vesicles is primed, and this fraction is defined as the readily releasable pool (RRP). Because of their unique functional state, primed vesicles can be readily quantified by application of hypertonic sucrose pulses. The hypertonic solution provides a $\mathrm{Ca}^{2+}$-independent mechanistic driving force that triggers within a few seconds the fusion of all RRP vesicles. The integral of the transient inward current produced by the concomitant release of glutamate is then a direct measure for the number

Received Nov. 10, 2006; revised Dec. 20, 2006; accepted Dec. 22, 2006.

This work was supported by a National Institutes of Health/National Institute of Neurological Disorders and Stroke Research Grant NS051262 (C.R.). We thank Hui Deng, Dr. Ralf B. Nehring, and Hongmei Chen for technical support and Dr. Erwin Neher for discussion and comments on this manuscript.

Correspondence should be addressed to Dr. Christian Rosenmund, Departments of Neuroscience and Molecular and Human Genetics, Baylor College of Medicine, One Baylor Plaza, Room 833E, Houston, TX 77030. E-mail: rosenmun@bcm.tmc.edu.

D0I:10.1523/JNEUROSCI.4908-06.2007

Copyright $\odot 2007$ Society for Neuroscience $\quad$ 0270-6474/07/271200-11\$15.00/0 of vesicles in the RRP in excitatory synapses (Rosenmund and Stevens, 1996).

Munc13s (mammalian Unc13) are presynaptic active zone proteins and essential priming factors. Munc13-deficient synapses fail to release vesicles during action potentials and sucrose stimuli, as well as spontaneously, whereas vesicle docking to the active zone is essentially normal (Aravamudan et al., 1999; Augustin et al., 1999; Richmond et al., 2001; Varoqueaux et al., 2002). Whereas the basic priming activity of Munc13-1 has been mapped to its C terminus (Basu et al., 2005; Madison et al., 2005; Stevens et al., 2005), the Munc13 N terminus has several modulatory domains, including a phorbol ester [ $4 \beta$-phorbol-12, 13dibutyrate $(\mathrm{PDBu})] /$ diacyglycerol (DAG) binding $\mathrm{C} 1$ domain. Although not essential for priming, proper $\mathrm{C} 1$ domain function is essential for survival in mice (Rhee et al., 2002). A single point mutation (H567K) in the Munc13-1 C1 domain abolishes phorbol ester binding, eliminates subsequent synaptic potentiation, and leads to dramatic changes in short-term plasticity characteristics. The RRP size is reduced in Munc13-1 ${ }^{\mathrm{H} 567 \mathrm{~K}}$ mutant neurons, but evoked response amplitudes are unaltered, resulting in a relatively higher vesicular release probability $\left(P_{\mathrm{vr}}\right)$ compared with wild-type (WT) neurons (Rhee et al., 2002). Based on these results, we hypothesized that the RRP comprises high and low $P_{\mathrm{vr}}$ subpools, and PDBu preferentially targets the low $P_{\mathrm{vr}}$ vesicles to increase their release probability. Synapses with $\mathrm{C} 1 \mathrm{domain} \mathrm{mu}-$ tant Munc13-1 ${ }^{\mathrm{H} 567 \mathrm{~K}}$ would thus lack the low $P_{\mathrm{vr}}$ pool, be insen- 
sitive to $\mathrm{PDBu}$, and simultaneously acquire a high $P_{\mathrm{vr}}$ phenotype. Apart from a mechanism that increases $P_{\mathrm{vr}}$ (Rhee et al., 2002; Rosenmund et al., 2002), it has been proposed that PDBu may also increase the RRP size in hippocampal cultured neurons (Stevens and Sullivan, 1998; Virmani et al., 2005).

To clarify the role of Munc13s in the PDBu-induced potentiation of release, we studied the effect of PDBu stimulation on $\mathrm{Ca}^{2+}$-dependent and -independent forms of release and used the Munc13-1 ${ }^{\mathrm{H} 567 \mathrm{~K}}$ knock-in (KI) C1 domain mutant mice to link the observed behavior to Munc13-1 C1 domain function.

\section{Materials and Methods}

Cell culture. Microdot neuronal cultures require previous preparation of astrocyte feeder wells. Clean $30 \mathrm{~mm}$ coverslips were placed in the culture plate wells and coated uniformly with $0.15 \%$ liquefied agarose gel (as an unfavorable cell-attachment substrate) using a sterile cotton swab. Once dry, a 1:4 mixture of rat-tail collagen and poly-D-lysine (PDL) was applied on top of the agarose using a custom-made dotted rubber stamp to form "microdots" on which cells readily attach. Four to $5 \mathrm{~d}$ before culturing the neurons, astrocytes were plated on the agarose-collagenPDL-coated coverslips, so that they formed a confluent monolayer of "microislands" for the autapses to grow. Once confluent, the astrocytes were treated with antimitotic $8 \mu \mathrm{M} 5$-fluoro-2' -deoxyuridine and $20 \mu \mathrm{M}$ uridine (FUDR) to halt the glial proliferation. The Munc13-1 ${ }^{\mathrm{H} 567 \mathrm{~K}} \mathrm{KI}$ mice die within $1-2 \mathrm{~h}$ after birth. Hence, newborn KI mice and their Munc13-1 WT and heterozygote (Het) littermates, both in the Munc13-2 knock-out background, were used for the primary neuronal cultures. Pups were decapitated according to the rules of the state animal welfare committee. Brains were removed and cleaned of meninges and vascular tissue, and hippocampi were dissected out in cold physiological HBSS. The hippocampal tissues of the desired genotypes were enzymatically dissociated with $2 \mathrm{U} / \mathrm{ml}$ papain in DMEM for $60 \mathrm{~min}$ at $37^{\circ} \mathrm{C}$. After enzyme inactivation at $37^{\circ} \mathrm{C}$ for 5 min using a solution of albumin, trypsin inhibitor, and 5\% FCS, the tissue was transferred to Neurobasal A medium containing B-27, $50 \mathrm{IU} / \mathrm{ml}$ penicillin, and $50 \mu \mathrm{g} / \mathrm{ml}$ streptomycin and gently triturated by passing through a narrow pipette tip. The cell suspension was plated onto FUDR-treated astrocyte feeder wells to a final cell density of $400-800$ cells $/ \mathrm{cm}^{2}$.

Solutions. Patch-pipette solutions included the following: $135 \mathrm{~mm} \mathrm{KCl}$, 10 mм HEPES, 1 mм EGTA, $4.6 \mathrm{~mm} \mathrm{MgCl}_{2}, 4 \mathrm{~mm} \mathrm{Na}$-ATP, $15 \mathrm{~mm}$ creatine phosphate, and $50 \mathrm{U} / \mathrm{ml}$ phosphocreatine kinase, $\mathrm{pH} 7.3,300$ $\mathrm{mOsm}$. The extracellular medium contained the following (in mM): 140 $\mathrm{NaCl}, 2.4 \mathrm{KCl}, 10 \mathrm{HEPES}, 10$ glucose, $4 \mathrm{CaCl}_{2}$, and $4 \mathrm{MgCl}_{2}$, pH $7.3(305$ mOsm). Hypertonic solutions for determining the RRP were prepared by using $250,500,750$, and $1000 \mathrm{~mm}$ sucrose in control external solution. Miniature EPSCs (mEPSCs) were measured in the standard external solution. Frequencies and amplitudes of false-positive events were regularly monitored by applying external solution containing $3 \mathrm{~mm}$ kynurenic acid for $2 \mathrm{~s}$ every $10 \mathrm{~s}$.

Experimental setup. Thick-walled borosilicate glass patch pipettes were pulled using a multistep puller (P-87; Sutter Instruments, Novato, CA), and pipette resistance ranged from 2 to $3 \mathrm{M} \Omega$. All solutions were applied using a fast-flow system that provides reliable and precise solution exchanges with time constants of $\sim 20-30 \mathrm{~ms}$ (Pyott and Rosenmund, 2002). Currents were recorded using an Axopatch 200B amplifier (Molecular Devices, Sunnyvale, CA). Series resistance was 70-75\% compensated. Data acquisition was controlled by Clampex 8 (Molecular Devices) on an IBM personal computer. Data were filtered using a low-pass eightpole Bessel filter at a rate of $5 \mathrm{kHz}$.

Electrophysiological controls. Electrophysiological recordings were performed at room temperature. The entire present dataset was acquired from three separate cultures, and the recorded values were pooled. Care was taken to record each day from a relatively equal number of cells per group for the three genotypes in question to prevent any ambiguities attributable to the developmental stage between the groups. The phorbol ester experiments were always paired, with the same protocols being recorded from each individual cell once in the absence of PDBu $(1 \mu \mathrm{M})$ and once in its presence. This ensured lower variability in the sample set.
For the sucrose gradient experiments, the order of the stimulation sequence $(500,250$, and $1000 \mathrm{~mm})$ and the application of PDBu were alternated, so that half of the cells were recorded in PDBu first, followed by washout and recording in control conditions and vice versa, to control for rundown. For control experiments to get a reliable estimate of nonspecific conductance during sucrose application, we used kynurenic acid ( $3 \mathrm{~mm}$ ) or NBQX $(3 \mu \mathrm{M})$ with the sucrose solution. To test how PDBu changes the speed of onset of responses to hypertonic solutions, we performed control experiments with added potassium chloride $(30 \mathrm{~mm})$. The resulting development of outward current was used to establish the time course of solution exchange for every flow pipe used and for all concentrations of hypertonic sucrose solutions.

Data analysis. Data were analyzed using AXOGRAPH software [version 4.9 (Molecular Devices) or AxographX (courtesy of Dr. John Clements, Axograph Scientific, Sydney, Australia)]. The sucrose response was normalized by its own area after subtracting the steady-state component, and the integral after "baselining" at onset was used to calculate the maximum slope of the sucrose-induced release. mEPSCs were detected by a template based event detection algorithm package. The release rate of EPSCs was estimated using a deconvolution algorithm, AxographX (Axograph Scientific). Graphs were plotted using Kaleidagraph software (Synergy Software, Reading, PA). Paired Student's $t$ test was applied to determine statistical significance of $p<0.05$.

\section{Results}

To study the role of $\mathrm{C} 1$ domain activation in neurotransmitter release, we directly compared three mouse genotypes belonging to the same litter: Munc13-1 WT and mice expressing one (Het) or two (KI) alleles of the Munc13-1 ${ }^{\mathrm{H} 567 \mathrm{~K}}$ mutation. All mice were Munc13-2-deficient to prevent any contribution of the Munc13-2 paralog. Most experiments were performed on glutamatergic autaptic hippocampal neurons 9-16 d in vitro. We also performed a separate set of experiments using wild-type neurons containing both Munc13-1 and Munc13-2 to compare excitatory and inhibitory synaptic transmission. To activate the $\mathrm{C} 1$ domain of Munc13-1, we used acute application of the agonist PDBu (1 $\mu \mathrm{M})$ and compared synaptic parameters before and during $\mathrm{PDBu}$ stimulation.

\section{Phorbol ester increases the rate of hypertonicity-induced vesicular release without increasing the RRP size}

Munc13s play an essential role in synaptic vesicle priming, and the $\mathrm{C} 1$ domain of Munc13-1 is required for acute potentiation of EPSCs by phorbol esters (Rhee et al., 2002). These findings support the idea that phorbol esters potentiate release by increasing the RRP (Stevens and Sullivan, 1998). Application of hypertonic solutions has been used to detect the RRP (Rosenmund and Stevens, 1996). Acute application of sucrose using a fast-flow system leads to the activation of two kinetically distinct components: a transient inward current signifying the release of all fusion competent vesicles, followed by a steady-state inward current component at the stage when the rate of pool refilling and the rate of release are at equilibrium. The area of the inward transient after subtracting the steady-state component represents the total amount of charge of the RRP. Normalization of this charge by the mean charge of the mEPSC renders the total number of vesicles in the RRP.

Our study shows that the total number of fusion-competent vesicles, as defined by the $500 \mathrm{~mm}$ sucrose response, in the Munc13-1 ${ }^{\mathrm{H} 567 \mathrm{~K}}$ knock-in mutant neurons is significantly reduced to $2299 \pm 300$ vesicles $(n=48)$, amounting to a $44 \%$ drop in RRP size compared with the WT average of $4109 \pm 772$ vesicles $(n=37)(p<0.05$, WT vs KI). This is in agreement with our previous study that used the same Munc13-1 ${ }^{\mathrm{H} 567 \mathrm{~K}}$ mutation in the Munc13-2 WT background (Rhee et al., 2002). The heterozy- 
gotes show influences of both the native and mutant Munc13-1 proteins and can release on average $2763 \pm 305$ vesicles $(n=43)(p<0.1$, Het vs KI) (Fig. $1 B, C)$. After a $60 \mathrm{~s}$ recovery from the sucrosemediated pool depletion, we treated a subset of these neurons with $\mathrm{PDBu}(1 \mu \mathrm{M})$ for 2 min and then applied the same concentration of sucrose to study the effect of phorbol esters on the RRP. We found that $\mathrm{PDBu}$ treatment does not change the size of the RRP in any of the groups under consideration ( $4092 \pm 873, n=28$, WT; $2814 \pm$ $384, n=29$, Het; $2467 \pm 399, n=31$, KI; all $p$ values $>0.5$, WT vs $\mathrm{WT}+\mathrm{PDBu}$, Het vs $\mathrm{Het}+\mathrm{PDBu}$, KI vs KI + PDBu).

Application of doubled concentrations of sucrose (1000 mM, for $3 \mathrm{~s}$ ) does not increase the charge released any further above the level achieved by $500 \mathrm{~mm}$ sucrose (4235 \pm 669 , WT; $4263 \pm 725$, $\mathrm{WT}+\mathrm{PDBu}, n=22$; $3252 \pm 398$, Het; $3108 \pm 484$; Het + PDBu, $n=23 ; 3095 \pm$ $490, \mathrm{KI} ; 2799 \pm 551, \mathrm{KI}+\mathrm{PDBu} ; n=19$ ), regardless of whether $\mathrm{PDBu}$ is present or not (Fig. 1D). This indicates that $500 \mathrm{~mm}$ sucrose is sufficiently strong a stimulus to cause the entire RRP to be released, and PDBu does not potentiate the pool size. Although stimuli of $500 \mathrm{~mm}$ or higher sucrose do not change the number of vesicles released, we can use hypertonic solutions of intermediate concentrations to test for changes in sensitivity of vesicles to the stimulus. We applied $250 \mathrm{~mm}$ sucrose (10 s) and quantified the transient component of the response, as a measure for the fraction of the pool released. PDBu increases the amount of release induced by $250 \mathrm{mM}$ sucrose by almost threefold in the case of WT $(2.88 \pm 0.32$ times naive WT; $n=22)$ and twofold in heterozygote $(1.89 \pm 0.20$ times naive Het; $n=23$ ) synapses (Fig. $1 D)$. The same submaximal stimulus applied in the presence of PDBu to the KI mutant neurons caused no change in the charge of the $250 \mathrm{~mm}$ sucrose-induced inward transient $(0.99 \pm 0.08$ times naive $\mathrm{KI} ; n=19$ ). However, to our surprise, the fraction of the pool released by naive KI neurons is equivalent to that of PDBu-treated WT synapses (72-81\% of their RRP) (Fig. $2 D)$. We note that, although the RRP of KI mutants is reduced to 2299 vesicles $(p<0.05)$, the number of vesicles released by $250 \mathrm{mM}$ in the KI group (2000 \pm 460 vesicles) exceeded that of the naive WT synapses (1100 \pm 300 vesicles).

These results show that activation of the Munc13-1 C1 domain increases the number of vesicles released only when the hypertonic stimulus is submaximal and does not cause any additional potentiation of responses during saturating osmotic challenges. This indicates that $\mathrm{C} 1$ domain activation does not affect the RRP per se but lowers the energy threshold for fusion of vesicles within the pool. The standard operational definition of

B
A $250 \mathrm{mM}$

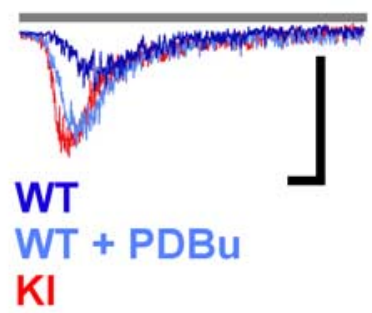

$500 \mathrm{mM}$

$1000 \mathrm{mM}$
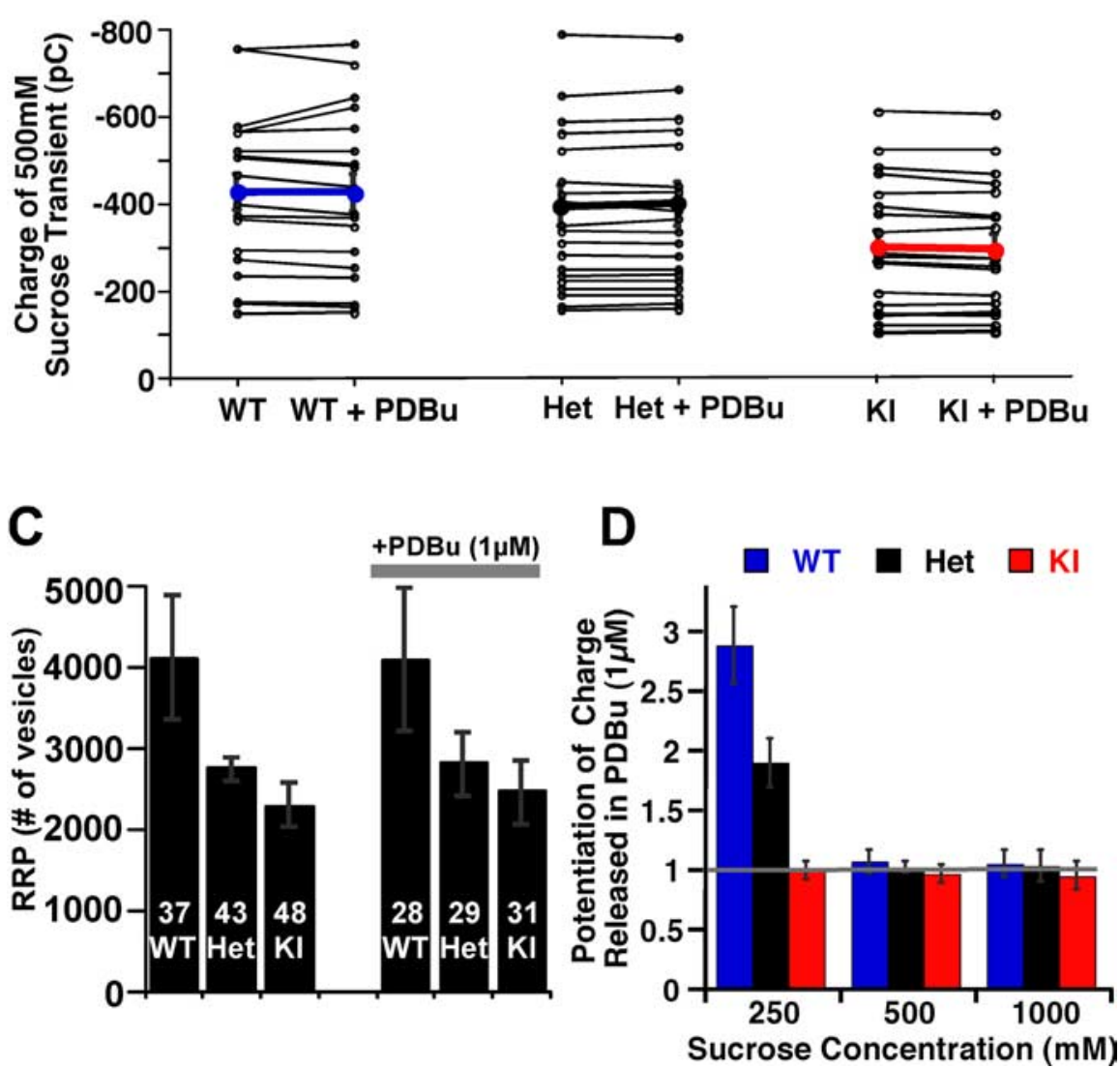

Figure 1. PDBu-mediated C1 domain activation does not affect the pool size. $A$, Exemplary raw traces of responses to $250 \mathrm{~mm}$ (left), $500 \mathrm{~mm}$ (middle), and $1000 \mathrm{~mm}$ (right) sucrose pulses in naive and PDBu (1 $\mu \mathrm{M}$ )-treated hippocampal autaptic neurons from Munc13-1 WT (dark blue), WT + PDBu (light blue), and Munc13-1H567K KI (red) mice. Gray bar above each trace indicates the duration of sucrose application. $\boldsymbol{B}$, Distribution of charge of the inward transient response to a $5 \mathrm{~s}$ application of $500 \mathrm{~mm}$ sucrose, in the presence and absence of PDBu in 19 individual neurons from WT (left), Het (middle), and KI (right) groups. Thick lines indicate the mean values for WT in blue, Het in black, and KI in red. C, Bar plot showing the mean number of vesicles in the RRP cells is indicated in white above each corresponding group. Error bars in this and the following figures indicate the SEM. $\boldsymbol{D}$, Potentiation of response charge during PDBu application at 250,500 , and $1000 \mathrm{~mm}$ sucrose stimuli.

RRP is the number of vesicles that represent the transient release activity during short application of highly hypertonic solutions (e.g., $500 \mathrm{~mm}$ sucrose) (Rosenmund and Stevens, 1996). At such high concentrations, PDBu will not increase the charge released, but it will at submaximal concentrations. Therefore, neither increased responses to submaximal sucrose concentrations nor increases in the peak amplitude of sucrose responses are evidence for a PDBu-induced increase in RRP. Accurate detection of RRP with hypertonic solutions may be impeded when solution exchange methods are used that cause a gradient in sucrose 
A
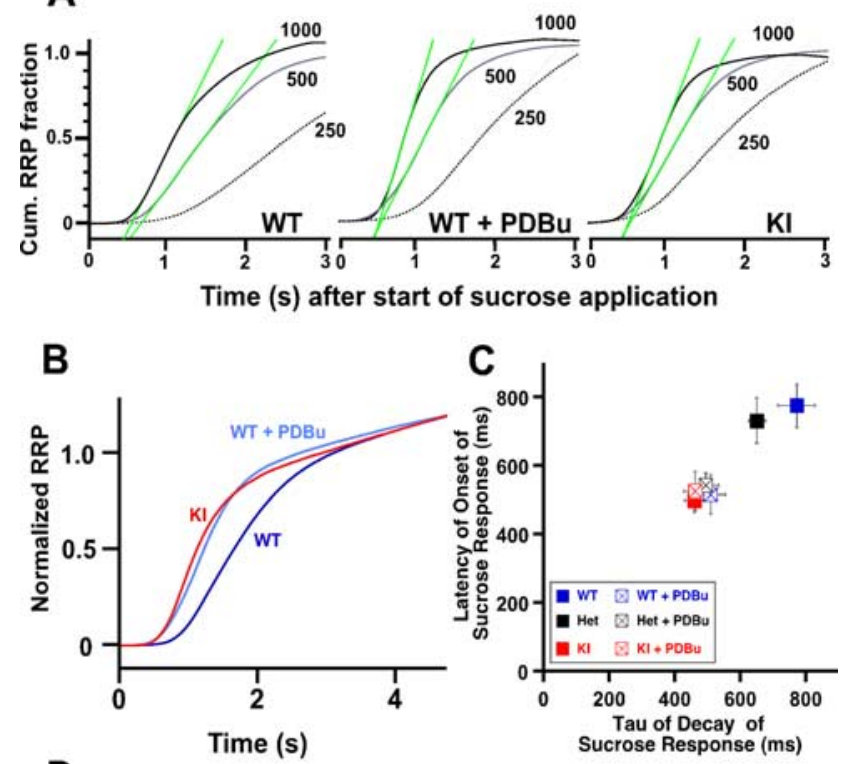

D

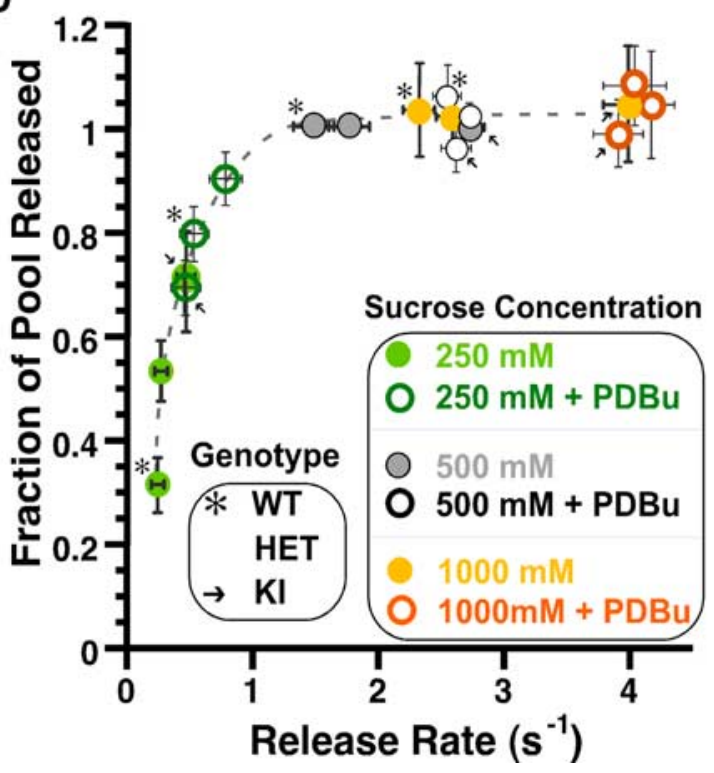

Figure 2. C1 domain activation and $\mathrm{H} 567 \mathrm{~K}$ mutation increase osmotically induced vesicular release rates. $\boldsymbol{A}$, Inverted mean current integrals for the three gradients of sucrose ( $1000 \mathrm{~mm}$ in black solid, $500 \mathrm{~mm}$ in gray solid, and $250 \mathrm{~mm}$ in black dotted lines) in WT (left), WT + PDBu (middle), and KI (right) normalized by their respective RRPs. The green lines depict the maximum slopes signifying the rate of release $\left(\mathrm{s}^{-1}\right)$ induced by that concentration of sucrose. $\boldsymbol{B}$, Average normalized current integrals showing the release time course of the RRP during $500 \mathrm{~mm}$ sucrose applications in WT (dark blue), WT + PDBu (light blue), and KI (red). C, Correlation between time constant of decay of the sucrose $(500 \mathrm{~mm})$ response and latency of onset of the response from the start of sucrose application. $\boldsymbol{D}$, Summary plot of the fraction of RRP released as a function of the maximal vesicular release rates. Data are from the three genotypes (WT marked with ${ }^{*}, n=22$; Het unmarked, $n=23$; and KI marked with $\rightarrow, n=19$ ) with (open symbols) or without (filled symbols) $1 \mu \mathrm{m}$ PDBu present and at the three sucrose concentrations $250 \mathrm{~mm}$ (green), $500 \mathrm{~mm}$ (gray), and $1000 \mathrm{~mm}$ (orange). All values are normalized to the RRP size (as defined by the response to $500 \mathrm{~mm}$ sucrose in the absence of PDBu) to determine the fraction of the pool released. Note that the data for $\mathrm{C} 1$ domain activation appears to mimic a virtual increase in hypertonic pressure, indicating an increased responsiveness to the stimuli.

concentration over space or time during application. This may interfere with distinguishing between changes in RRP size and fusion efficacy and may explain different results from different studies in the same experimental system (Stevens and Sullivan, 1998; Virmani et al., 2005).
These results also provide insights into the state of primed vesicles in the $\mathrm{C} 1$ domain mutant synapses: the $\mathrm{H} 567 \mathrm{~K}$ is a gainof-function mutation that causes the mutant synapses to mirror the PDBu-stimulated state of WT synapses in their sensitivity to submaximal osmotic stimuli. Because PDBu does not affect RRP size, we can conclude that acute activation of the Munc13 C1 domain is independent of the priming function of Munc13. Hence, mutations that lead to disruption of $\mathrm{C} 1$ domain $\mathrm{PDBu}$ binding should not affect RRP size. However, the absolute RRP size in the KI neurons is reduced by $44 \%$, which is puzzling. Initially, we explained this via a two-pool model, in which the mutant suffers a selective elimination of a low $P_{\mathrm{vr}}$, PDBusensitive subpool of vesicles. Given our finding that the mutation is a gain-of-function mutation and that, at intermediate sucrose concentrations, it is able to release more vesicles than wild-type synapses challenges the validity of our initial two-pool model in the context of PDBu modulation of vesicle release. We therefore consider alternative possibilities to explain the reduced pool size in the mutant neurons. The loss of some primed vesicles may be related to interference with the neighboring Munc13 N-terminal RIM (Rab3-interacting molecule)-binding C2A domain (Brose et al., 1995; Lu et al., 2006), which is more directly involved in the early steps of priming. Munc13 N-terminus deletion (Betz et al., 2001) and mutations in Munc13-binding regions of RIM (Dulubova et al., 2005) and RIM-interacting regions in Munc13 C2A domain (Andrews-Zwilling et al., 2006) (J. Basu, C. Rosenmund, J. Lu, and J. Rizo, unpublished observations) causes up to $50 \%$ reduction in pool size. Alternatively, the constitutively increased release activity in the KI mutant may have lead to a homeostatic downregulation of RRP size.

\section{C1 domain activation of Munc13-1 leads to accelerated vesicle release kinetics}

If the Munc13-1 C1 domain activation increases release as a result of a lowered energy barrier for fusion, we would expect the kinetics of the sucrose response to be accelerated and the onset time shortened. In support of this, as is apparent for the raw traces in Figure $1 A$, the peak of the sucrose responses in PDBu are larger and shifted to the left compared with the control conditions.

To test the lowered energy barrier model, we set out to quantify the time course of release of responses to hypertonic stimuli. To quantify the release rate of individual vesicles, we normalized the individual responses in 250,500, and $1000 \mathrm{~mm}$ sucrose of each cell to its corresponding RRP (the value of the response to 500 $\mathrm{mM}$ ). Then we integrated the normalized response and quantified the maximal slope as a measure for peak release rate. We corrected this slope for the amount of vesicles that had already been depleted (Fig. 2A). In the WT naive neurons, $250 \mathrm{~mm}$ sucrose releases individual vesicles at a peak rate of $0.21 \pm 0.02 \mathrm{~s}^{-1}$, whereas this rate increased approximately sevenfold in $500 \mathrm{mM}$ sucrose $\left(1.51 \pm 0.06 \mathrm{~s}^{-1} ; n=22\right)$ and 11 -fold $\left(2.34 \pm 0.07 \mathrm{~s}^{-1}\right)$ with $1000 \mathrm{~mm}$ sucrose (Fig. $2 A, D$ ). Thus, as expected, the release rate increases with the amount of osmotic energy supplied in a dose-dependent manner. Comparison with the subsequent sucrose response in the presence of $\mathrm{PDBu}$ showed that the release rate doubled in WT neurons when $250 \mathrm{~mm}$ sucrose was applied, whereas the KI group showed rates similar to the WT + PDBu group and did not change during application of $\mathrm{PDBu}(0.47 \pm$ $0.03 \mathrm{~s}^{-1}$ in KI; $0.53 \pm 0.06 \mathrm{~s}^{-1}$ in WT + PDBu; $0.47 \pm 0.06$ in $\mathrm{KI}+\mathrm{PDBu}$ ). Even at the two higher concentrations of sucrose, the release rate remained $30-40 \%$ higher in the $\mathrm{C} 1$ activated WT and in the Munc13-1 ${ }^{\mathrm{H} 567 \mathrm{~K}} \mathrm{KI}$ mutant group compared with the naive WT group (500 mm sucrose: $2.55 \pm 0.10 \mathrm{~s}^{-1}$, WT + PDBu, 
$n=22 ; 2.76 \pm 0.09 \mathrm{~s}^{-1}, \mathrm{KI}, n=19 ;$ and $1000 \mathrm{mM}: 4.04 \pm 0.14$ $\left.\mathrm{s}^{-1}, \mathrm{WT}+\mathrm{PDBu} ; 3.99 \pm 0.12 \mathrm{~s}^{-1}, \mathrm{KI}\right)$. This shows that activation of the Munc13-1 C1 domain accelerates vesicular release in general, consistent with the model of a lowered energy barrier for fusion. In addition, as seen previously, the Munc13-1 ${ }^{\mathrm{H} 567 \mathrm{~K}} \mathrm{C1}$ mutant mimics $\mathrm{PDBu}$-mediated $\mathrm{Cl}$ domain activation (Fig. $2 B, D)$.

A lowered energy barrier should also decrease the onset time of the sucrose response. We quantified the delay between start of application of $500 \mathrm{~mm}$ sucrose and the onset of the response by extrapolating from the rising phase of the sucrose response the point of intercept with the zero baseline. We analyzed the acceleration of the response onset because of $\mathrm{C} 1$ domain activation by two means. First, we averaged the actual time taken by each response in the various groups and then calculated the difference between their mean values of onset. This provided an $\sim 250-300$ $\mathrm{ms}$ acceleration of RRP release onset in the naive KI groups compared with naive WT (Fig. 2C). Second, we used the intrinsic relative shift in onset of the response seen in the WT group before and after PDBu was applied. This method does not allow for proper cross comparison between the three genotypes but provides superior signal-to-noise ratios within a group, because it is not sensitive to cell-to-cell variability. We found that activation of the $\mathrm{C} 1$ domain accelerated onset of release at $500 \mathrm{~mm}$ sucrose by $207 \pm 37 \mathrm{~ms}$, whereas as expected, no acceleration was observed in the KI group.

The third form of kinetic characterization focused on decay kinetics of the sucrose response. An acceleration of release in the $\mathrm{C} 1$ domain-activated state should result in accelerated decay kinetics attributable to faster pool depletion. We fitted a single exponential to the decay and found that the decay kinetics were accelerated in the WT $+\mathrm{PDBu}$ and in the KI group (WT, $772 \pm$ $56 \mathrm{~ms}$; WT + PDBu, $508 \pm 47 \mathrm{~ms}$; KI, $458 \pm 29 \mathrm{~ms}$; KI + PDBu, $462 \pm 36 \mathrm{~ms}$ ) (Fig. 2C). In addition, both onset of release and the time constant of decay correlated well among the different groups.

Together, the detailed analysis of the kinetics of the hypertonic sucrose-induced release after PDBu treatment or in KI neurons revealed a secretion behavior that reflects a lowered energy barrier for fusion. In Figure 2D, we summarize the data (from Figs. $1 D, 2 A$ ) by correlating release rates with the fraction of pool released under conditions of variable sucrose concentrations, variable genotypes, and presence or absence of $\mathrm{PDBu}$. The trend of the data indicates that, across the above conditions, increasing osmolarity and activating the $\mathrm{C} 1$ domain result in similar changes, an accelerated fusion rate in vesicles derived from the $\mathrm{RRP}$. We generally measure the RRP as a charge integral of the transient inward current in response to sucrose from which the steady-state component is subtracted. At steady state, release and refilling are at equilibrium. The transient represents the RRP, as long as the release rate is much faster than the refilling rate, and this can be seen with the fraction of RRP reaching 1 at concentrations of 500 and $1000 \mathrm{~mm}$ sucrose. At concentrations of sucrose at which the release rate is close to the refilling rate (e.g., at $250 \mathrm{mM}$ ), the transient current component is a small fraction of RRP and displays high sensitivity to changes in release rate. At such a sensitive range, changes in energy barrier for fusion would be reflected in potentiation of vesicular fusion rates coupled with an increase in the fraction of the pool released. So, with both of these parameters, maximal release rate and fraction of pool released, we probe the same change in fusion willingness during $\mathrm{C} 1$ domain activation. As depicted in green for $250 \mathrm{~mm}$ sucrose in Figure $2 \mathrm{D}$, activation of the $\mathrm{C} 1$ domain by PDBu or $\mathrm{H} 567 \mathrm{~K} \mathrm{mu}$ - tation lowers the overall energy barrier for fusion of vesicles, so many more vesicles overcome the detection limiting refilling rate and hence with the same submaximal stimulus a far greater fraction of vesicles from the pool (70-90\%) can be measured, releasing at an increased rate $\left(\sim 0.5-1 \mathrm{~s}^{-1}\right)$. Conversely, for saturating concentrations of sucrose (500 and $1000 \mathrm{~mm}$ ), all vesicles release at a rate $\left(\sim 1.5-2 \mathrm{~s}^{-1}\right)$ that far exceeds the refilling rate, and the entire RRP is detected in the sucrose transient. So any shift in the energy barrier for fusion would be detected in terms of increases in the peak release rate of vesicles $\left(\sim 2.5-4 \mathrm{~s}^{-1}\right)$ and not the number of vesicles as represented by the plateau phase of the plot in Figure $2 D$.

Separate experiments that looked at paired-pulse sucrose response showed significantly faster recovery in PDBu-treated WT neurons compared with untreated neurons (supplemental Fig. 1, available at www.jneurosci.org as supplemental material). This finding is in agreement with the finding of Stevens and Sullivan (1998) and could reflect a secondary function of C1 domain activation on the rate at which the RRP is replenished. Conversely, the faster recovery of the hypertonic response could also be the result of the increased sensitivity of the vesicle to be detected by the same stimulus. Although there is no formal evidence, a lowered energy barrier for fusion attributable to C1 domain activation would increase the chances of vesicles that are partially primed to fuse in response to the same stimulus. Furthermore, considering that vesicles from the KI mutant have a lower energy barrier for fusion, one would expect faster recovery compared with wild type. However, in our previous paper (Rhee et al., 2002), the H567K mutant pool recovered at the same rate as the wild-type RRP. In light of the observation that the KI mutant is defective in priming, there is a possibility that, although vesicular release rate is faster than the wild type, the recovery of the pool after depletion is offset to the wild-type level.

Finally, the fact that hypertonic solution releases vesicles in a $\mathrm{Ca}^{2+}$-independent manner implies that above modification in fusion efficacy is independent of $\mathrm{Ca}^{2+}$ triggering. To confirm this notion, we analyzed spontaneous release, another form of $\mathrm{Ca}^{2+}$ independent release.

\section{C1 domain activation increases the frequency and rate of spontaneous release}

We measured spontaneous mEPSCs in our three genotypes in the presence and absence of PDBu $(1 \mu \mathrm{M})$. Data were acquired for a period of $60 \mathrm{~s}$ (six episodes, $10 \mathrm{~s}$ each) for each condition and genotype. Each $10 \mathrm{~s}$ period included a $2 \mathrm{~s}$ application of saturating concentrations (3 $\mathrm{mm}$ ) of the AMPA receptor antagonist kynurenic acid to block all postsynaptic responses (Fig. $3 A$, top trace). This served as an internal control for detection of "falsepositive" spontaneous events (Wojcik et al., 2004).

We found that, compared with the naive WT group, the absolute frequency of mEPSCs is more than doubled in the phorbol-"resistant" mutant neurons from Munc13-1 ${ }^{\mathrm{H} 567 \mathrm{~K}} \mathrm{KI}$ mice and in the phorbol ester-treated WT neurons (Fig. 3B). We did not observe any difference in the charge, amplitude, and shape (half-width) of mEPSC events among the three different genotypes, regardless of whether they were treated with $\mathrm{PDBu}$ or not (Fig. $3 A, C$ ).

We then calculated the spontaneous release rate by dividing mEPSC frequency by the number of vesicles in the RRP. We found that vesicles from naive WT neurons have the lowest spontaneous release rate of $0.0022 \pm 0.0007 \mathrm{~s}^{-1}(n=37)$, corresponding to a mean dwell time of $454 \mathrm{~s}$ before individual vesicles fuse. The spontaneous release rate can be potentiated up to four times 
A
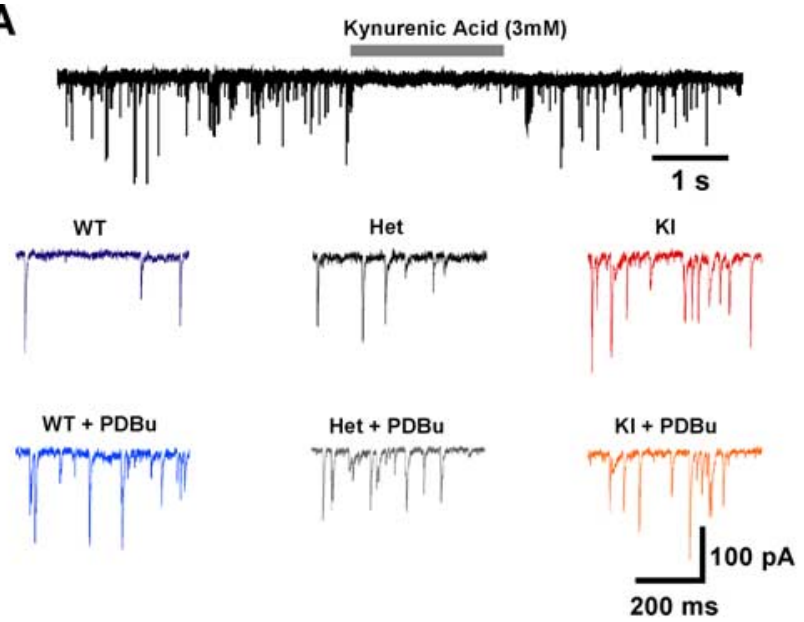

B

C
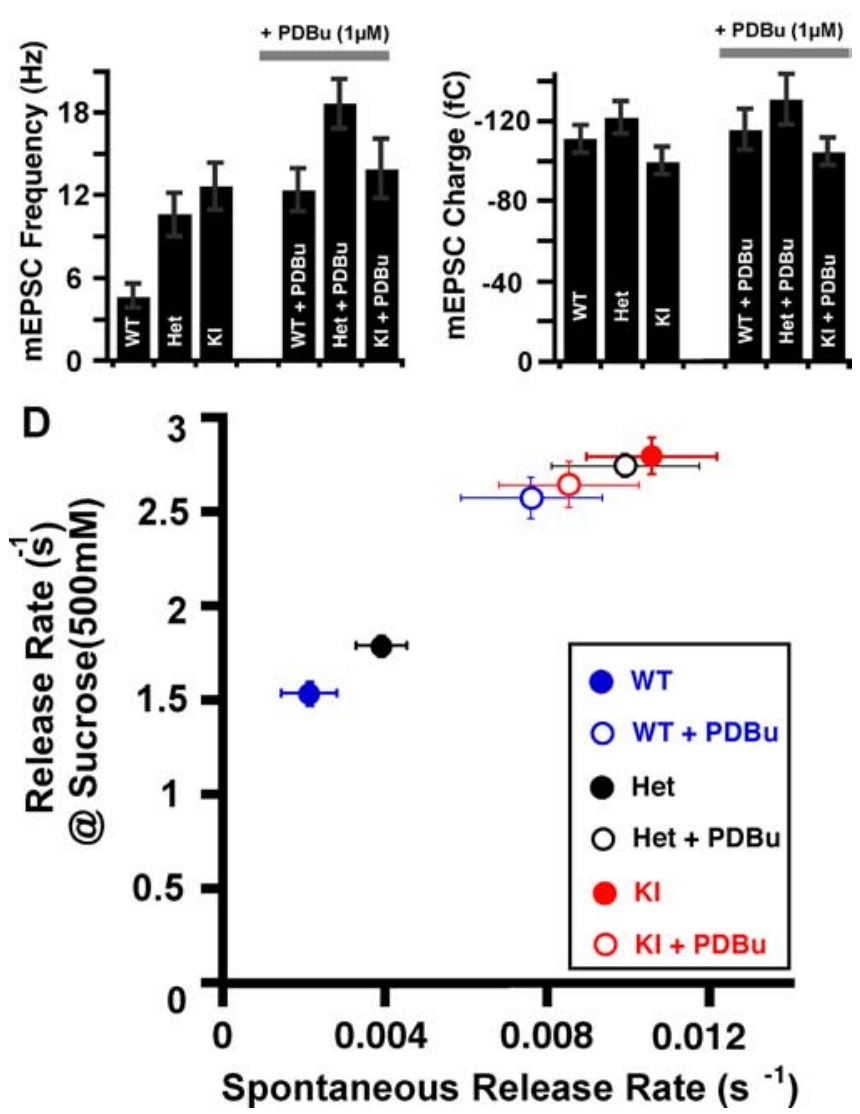

Figure 3. Increase in the frequency and rate of release of spontaneous events during $\mathrm{C1}$ activation. $\boldsymbol{A}$, Top, Trace showing the $10 \mathrm{~s}$ mEPSC acquisition protocol with a $2 \mathrm{~s}$ period of kynurenic acid (3 mM) for background noise detection. Bottom, A $500 \mathrm{~ms}$ span of raw traces showing the spontaneous activity in the three genotypes WT (blue), Het (black), and KI (red) and in the presence of $\mathrm{PDBu}$ (light blue, gray, and orange, respectively). $\boldsymbol{B}$, Bar plot of absolute mEPSC frequencies in KI, Het, and KI without (left) and with (right) PDBu present. C, mEPSC charge in the same groups and conditions as in $\boldsymbol{B}$. Charge released during a single spontaneous event $(n=40, \mathrm{WT} ; n=55$, Het; $n=49, \mathrm{Kl} ; n=28$, WT + PDBu; $n=29$, Het + PDBu; and $n=31, \mathrm{KI}+\mathrm{PDBu})$. $\boldsymbol{D}$, Strong correlation between spontaneous release rate and $500 \mathrm{~mm}$ sucrose maximal induced release rate in the three groups and two conditions.

$\left(0.0076 \pm 0.0017 \mathrm{~s}^{-1} ; n=28\right)$, with $1 \mu \mathrm{M}$ PDBu. The KI mutant already exhibits similarly elevated release rates $(0.0105 \pm 0.0016$ $\left.\mathrm{s}^{-1} ; n=48\right)$, and treating them with $\mathrm{PDBu}$ is ineffective $\left(0.0085 \pm 0.0017 \mathrm{~s}^{-1} ; n=31, \mathrm{KI}+\mathrm{PDBu}\right)$. The heterozygotes have an intermediate spontaneous release rate of $0.0039 \pm 0.0016$ $\mathrm{s}^{-1}(n=43)$, which is increased to $0.0099 \pm 0.0018 \mathrm{~s}^{-1}(n=29)$ during $\mathrm{C} 1$ domain activation by $\mathrm{PDBu}$ (Fig. $3 D$ ).

The increased basal release activity during $\mathrm{C} 1$ domain activation, just as in the case of responses to hypertonic stimuli, finds its simplest explanation in a lowered energy barrier for vesicle fusion. Consistent with this is the observation that both forms of release, although differing in their absolute rates by three orders of magnitude, showed very strong correlation in behavior when we considered the activation state of the Munc13-1 C1 domain (Fig. 3D). We next wanted to test whether the observed increases in $\mathrm{Ca}^{2+}$-triggered release during phorbol ester treatment (Fig. 4) may thus be the result of the same phenomenon underlying the shift in $\mathrm{Ca}^{2+}$-independent release.

$\mathrm{C} 1$ domain activation increases the rate of $\mathrm{Ca}^{2+}$-triggered release in correlation with $\mathrm{Ca}^{2+}$-independent release rates We evoked EPSCs with 2-ms-long, $70 \mathrm{mV}$ depolarizations at a frequency of $0.2 \mathrm{~Hz}$. We found, in agreement with our previous findings in Munc13-1 ${ }^{\mathrm{H} 567 \mathrm{~K}}$ mutant neurons on the Munc13-2 WT background (Rhee et al., 2002), that all three experimental groups have similar EPSC amplitudes $(2.95 \pm 0.69 \mathrm{nA}, n=37$, WT; $2.68 \pm 0.52 \mathrm{nA}, n=43$, Het; and $2.64 \pm 0.71 \mathrm{nA}, n=48, \mathrm{KI})$ (Fig. $1 B$ ). The H567K C1 domain mutation does not change the EPSC charge $(24.7 \pm 6.9 \mathrm{pC}, n=37, \mathrm{WT} ; 25.1 \pm 5.0 \mathrm{pC}, n=43$, Het; and $25.2 \pm 6.8 \mathrm{pC}, n=48, \mathrm{KI})$, indicating that both synchronous and asynchronous releases are essentially unaltered in these mutant mice. We applied PDBu in control external solution for $1 \mathrm{~min}$ to the neurons and monitored the evoked responses over time using the same $0.2 \mathrm{~Hz}$ stimulus paradigm. The effect of phorbol esters was obvious in the first response after PDBu application, and the responses reached a maximum with the second or third response. We quantified the change of EPSC amplitude and charge attributable to phorbol esters and found that, in WT, responses increased almost twofold in the case of amplitude $(1.92 \pm 0.15 ; n=28)$ (Fig. $1 A, C)$ and more than twofold in the case of charge $(2.48 \pm 0.22 ; n=28)$. In contrast, the Munc13$1^{\mathrm{H} 567 \mathrm{~K}}$ mutants seemed to be unaffected by phorbol esters (amplitude, $2.95 \pm 0.71 \mathrm{nA}$; charge, $29.77 \pm 6.54 \mathrm{pC} ; n=31$, $\mathrm{KI}+$ $\mathrm{PDBu}$ ). The neurons derived from heterozygous mice, expressing both Munc13-1 WT and the H567K C1 domain mutant proteins, show intermediate responses to phorbol ester stimulation (1.42 \pm 0.06 , normalized amplitude; $1.56 \pm 0.08$, normalized charge; $n=29$, Het $+\mathrm{PDBu}$ ). The intermediate phenotype of the heterozygous group shows that both the WT and mutant proteins act independently and with overall similar efficacy.

To determine the rate at which vesicles are released at the peak of an evoked response, we normalized the peak amplitude of the EPSC by the corresponding charge of the RRP and deconvolved the response with the mEPSC shape (Rhee et al., 2005). Munc13-1 WT containing neurons that release individual vesicles occur at a peak rate of $23.5 \pm 1.3 \mathrm{~s}^{-1}(n=37)$, whereas heterozygous neurons have a peak release rate of $37.8 \pm 2.1 \mathrm{~s}^{-1}$ $(n=43)$ and the KI mutants release at almost three times the WT rate, at $63.5 \pm 2.1 \mathrm{~s}^{-1}(n=48)$. Phorbol esters potentiate the WT and heterozygote EPSC release rates to a level similar to that seen in the Munc13- $1^{\mathrm{H} 567 \mathrm{~K}} \mathrm{C} 1$ domain mutant $\left(65.4 \pm 4.9 \mathrm{~s}^{-1}, n=\right.$ 28, WT + PDBu; $64.4 \pm 3.9 \mathrm{~s}^{-1}, n=29$, Het + PDBu). The vesicular release rate of the PDBu-treated KI group was unchanged compared with its non-PDBu control state $(67.4 \pm 2.2$; $n=31, \mathrm{KI}+\mathrm{PDBu} ; p>0.1)$. Although all three forms of release (spontaneous, hypertonic, and $\mathrm{Ca}^{2+}$ triggered) vary more than four orders of magnitude in absolute release rates, changes in release as a function of genotype or as a function of activity of the 
A
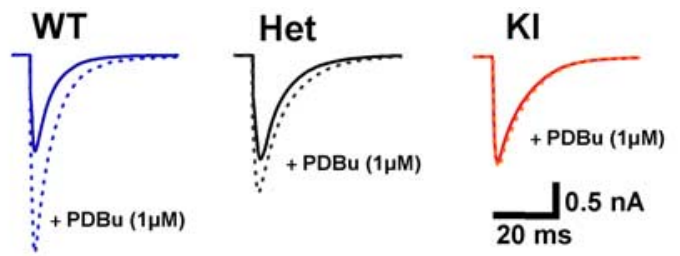

B

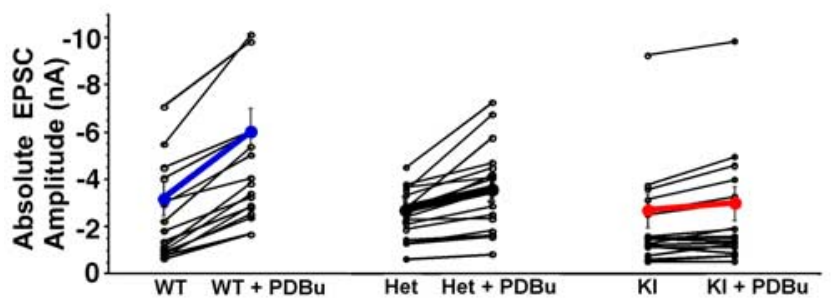

C

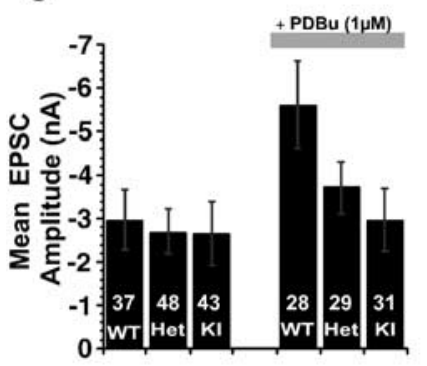

D

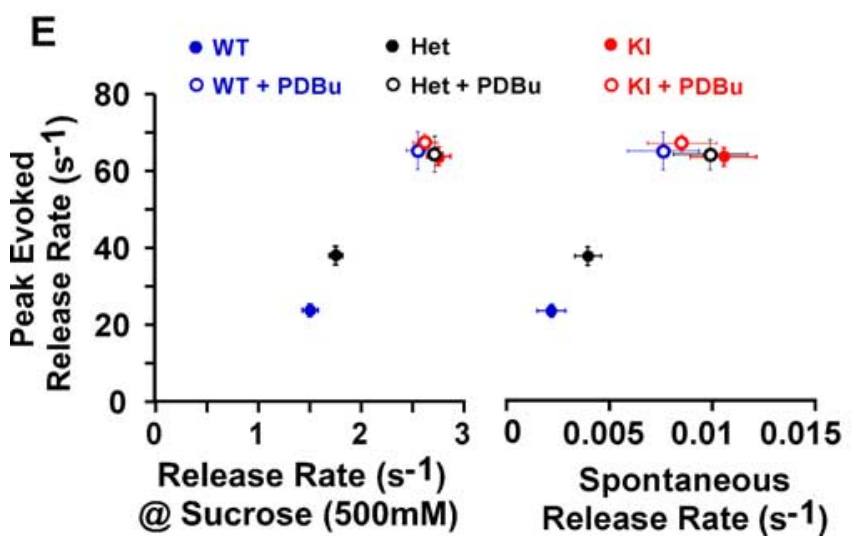

Figure 4. C1 domain activation increases the rates of all forms of release. $A$, Exemplary EPSC traces from WT (blue), Het (black), and KI (red) groups and the effect of PDBu (dotted lines). $\boldsymbol{B}$, Scatter plot of 19 individual neurons. C, D, Bar plots of PDBu-induced potentiation of EPSCS. The absolute amplitudes in naive neurons from the three groups are identical ( $\boldsymbol{C}$, left). $\boldsymbol{E}$, Correlation of vesicular release rates during all the three forms of release: $\mathrm{Ca}^{2+}$ evoked ( $y$-axis), $500 \mathrm{~mm}$ sucrose induced ( $x$-axis, left), and spontaneous ( $x$-axis, right). The peak evoked release rate was calculated by deconvolution of individual EPSC responses by their corresponding mEPSCs after normalizing the EPSC by the RRP of that cell. The osmotically induced release rate was derived from the mean of the maximum slope of $500 \mathrm{~mm}$ sucrose response integrals normalized by the corresponding RRP and corrected for by taking into account the fraction of the pool already depleted at the peak of the response. Spontaneous release rate was obtained from the average ratio of the frequency of mEPSCs of each cell to its RRP.

Munc13-1 C1 domain were highly correlated (Fig. 4E). This strong correlation between spontaneous, osmotically induced, and evoked release processes coupled with the fact that Munc13 deletion results in loss of all forms of neurotransmitter release (Varaqueaux et al., 2002), suggest that they all undergo similar forms of modulation. This strongly speaks for a common constitutive mechanism in which vesicles for spontaneous and activity-
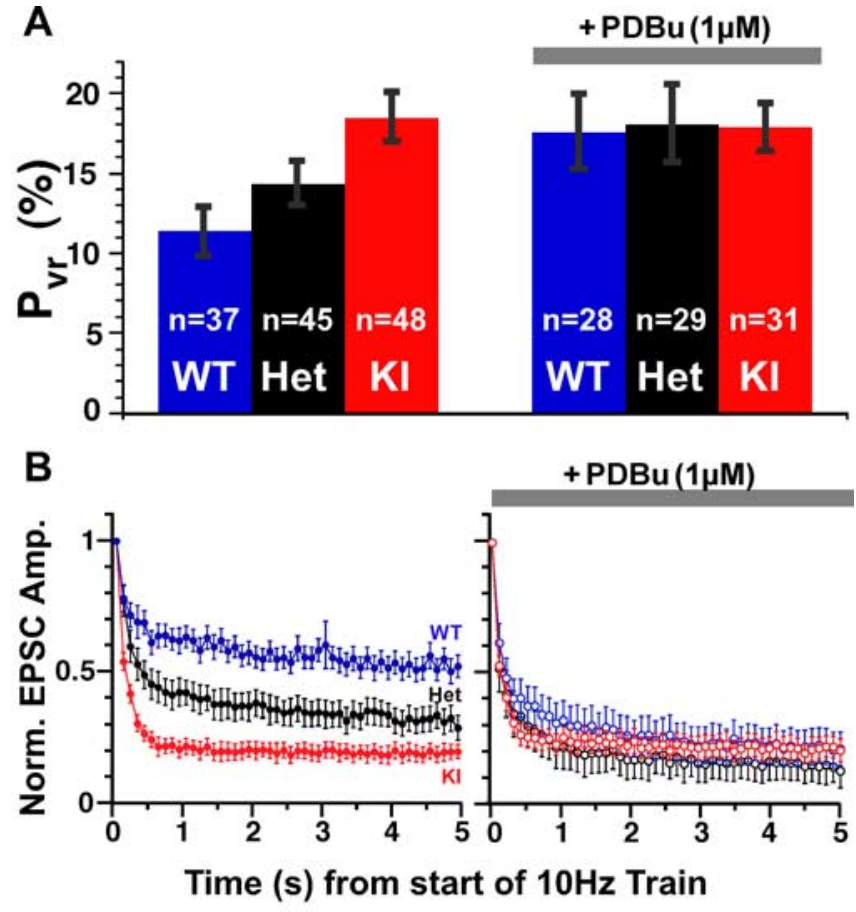

C
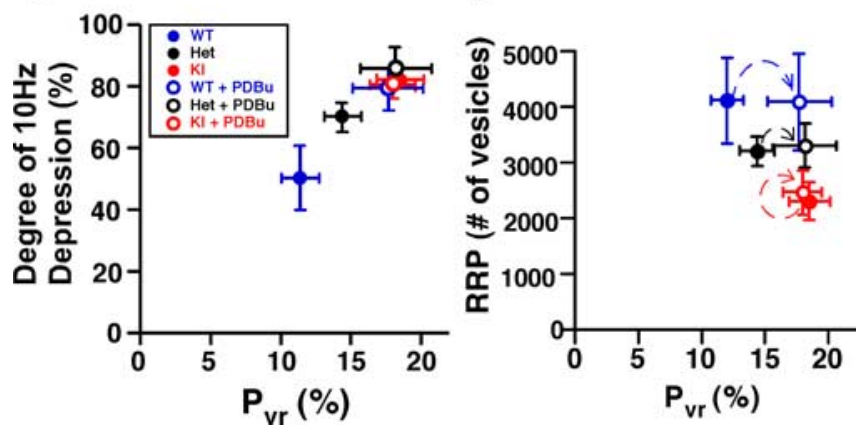

Figure 5. Munc13-1 1 domain increases vesicular release probability. $A$, Bar plot quantifying the vesicular release probability ( $P_{\mathrm{v} r}$, percentage) showing that the activation of the $\mathrm{C1}$ domain and $\mathrm{H} 567 \mathrm{~K}$ mutation lead to an increased $P_{\mathrm{vr}}$ The KI mutant does not show any additional increase in $P_{\mathrm{vr}}$ during PDBu treatment. $\boldsymbol{B}$, Normalized synaptic responses from wild-type (blue), heterozygote (black), and KI mutant (red) neurons during $10 \mathrm{~Hz}$ spike train (5s) in the absence (left, filled circles) and presence (right, open circles) of PDBu (1 $\mu \mathrm{M})$. C, Plot of the degree of depression during the $10 \mathrm{~Hz}$ spike train as a function of $P_{\mathrm{yr}}$ for each group examined in the presence and absence of PDBu. D, Plot of RRP size versus $P_{\text {vr }}$ before (filled symbols) and after (open symbols) PDBu application. $\boldsymbol{D}$, Same groups as in $C$.

dependant release are derived from essentially one pool and argues against the idea proposed by Virmani et al. (2005) that phorbol esters selectively regulate a so-called "activity-dependent recycling pool" and spare spontaneous vesicle recycling.

Enhancement of vesicular release probability with $\mathrm{C} 1$ domain activation

Above data taken together imply that Munc13-1 C1 domain activation induces an increase of EPSC amplitude without changing RRP size, hence increasing $P_{\mathrm{vr}}$. The $P_{\mathrm{vr}}$ value can be computed by dividing the charge of the EPSC by the charge of the RRP, and, as expected, the overall $P_{\mathrm{vr}}$ is increased during Munc13-1 C1 activation (Fig. 5A). Whereas in WT Munc13-1 neurons, vesicles initially release with a probability of $11.4 \pm 1.2 \%$, phorbol esterinduced activation of the Munc13-1 C1 domain increases $P_{\mathrm{vr}}$ to $17.7 \pm 2.5 \%$. Again consistent with the previous measure- 
ments, the $\mathrm{C} 1$ domain mutant mimics the activated state by showing a high $P_{\mathrm{vr}}$ of $18.6 \pm 1.6 \% . P_{\mathrm{vr}}$ in these synapses was insensitive to any additional modification by $\mathrm{PDBu}(18.0 \pm$ $1.5 \%)$, and furthermore the heterozygous group fell between the WT and KI groups (Het naive, $14.4 \pm 1.2 \%$; Het $+\mathrm{PDBu}$, $18.2 \pm 2.4 \%)$.

Short-term plasticity characteristics are strongly affected by modulation of $P_{\mathrm{vr}}$. For example, pure wild-type neurons that show $13-32 \%$ facilitation of EPSC amplitudes when stimulated with paired pulses at intervals of 20-40 ms depress in the presence of PDBu by $\sim 35-40 \%$ (supplemental Fig. 2, available at www.jneurosci.org as supplemental material). The Munc13$1^{\mathrm{H} 567 \mathrm{~K}} /$ Munc13-2 WT expressing neurons showed levels of paired-pulse depression similar to the Munc13-1/Munc13-2 WT neurons treated with PDBu (Rhee et al., 2002). Furthermore, the time course of the change in EPSC amplitude during $10 \mathrm{~Hz}$ action potential trains (50 stimuli) followed similar patterns. Moderate steady-state depression in the naive wild-type neurons was converted to strongly depressing time courses in the presence of $\mathrm{PDBu}$ or in the Munc13-1 ${ }^{\mathrm{H} 567 \mathrm{~K}} \mathrm{KI}$ mutant neurons. We quantified the degree of depression by comparing the average amplitudes of the last 10 responses at the end of the train with the average steady-state amplitude before the train. The EPSC amplitudes in WT neurons undergo $50.1 \pm 9.7 \%(n=22)$ depression, whereas Het animals show a $69.9 \pm 4.3 \%(n=29)$ decline and the KI mutants depress by $81.9 \pm 2.7 \%(n=39)$ during the 10 $\mathrm{Hz}$ spike train (Fig. 5B). PDBu increases the level of depression quite severely in Munc13-1 WT and heterozygote responses to $79.5 \pm 6.4$ and $85.9 \pm 5.9 \%$ of their starting amplitudes, respectively (Fig. $5 C$ ). The already elevated level of spike train depression in the $\mathrm{H} 567 \mathrm{~K}$ mutant does not change in the presence of $\mathrm{PDBu}(80.6 \pm 3.8 \%$, KI $+\mathrm{PDBu})$. The $10 \mathrm{~Hz}$ depression pattern of phorbol ester-treated WT and Het cells is almost duplicated in the KI mutant group, indicating that the activity-dependent short-term plasticity characteristics of the Munc13-1 C1 domain activated and mutated states are practically equivalent. We then correlated $P_{\mathrm{vr}}$ with the degree of spike train depression to illustrate how initial release probability determines synaptic depression (Fig. 5C). Increases in $P_{\mathrm{vr}}$ attributable to $\mathrm{C} 1$ domain activation have, however, no impact on the RRP (Fig. 5D).

\section{Regulation of release rate of GABAergic vesicles}

To study whether the potentiation of vesicular release via the activation of the $\mathrm{C} 1$ domain of Munc13-1 is a general phenomenon, we performed a comparative study of the effects of PDBu on pure wild-type GABAergic and glutamatergic hippocampal neurons. We first noted that potentiation of PSCs were very similar in the GABAergic inhibitory cells and glutamatergic excitatory neurons (1.86 $\pm 0.09, n=129$, EPSC, glutamatergic; $1.79 \pm 0.13$, $n=51$, IPSC, GABAergic) (Fig. 6A,D). Similar to excitatory neurons, the RRP size of inhibitory neurons were also not potentiated by PDBu treatment (Fig. $6 D$ ), but their release kinetics were accelerated (Fig. 6B,C). However, the calculated $P_{\mathrm{vr}}$ for naive inhibitory neurons was twice as high compared with their glutamatergic counterparts $(18.5 \pm 1.2 \%$, naive GABAergic; $7.8 \pm$ $0.7 \%$, naive glutamatergic), and the kinetics of sucrose-mediated release was 37\% faster in the GABAergic cells $\left(2.01 \pm 0.12 \mathrm{~s}^{-1}\right)$ compared with the glutamatergic neurons $\left(1.46 \pm 0.10 \mathrm{~s}^{-1}\right)$ (Fig. $6 E)$. PDBu causes $P_{\mathrm{vr}}$ and osmotically induced release rate in both types of neurons to potentiate in a similar manner by 1.7 - to 2.1-fold. These results have important implications. First, hippocampal inhibitory neurons appear to undergo similar
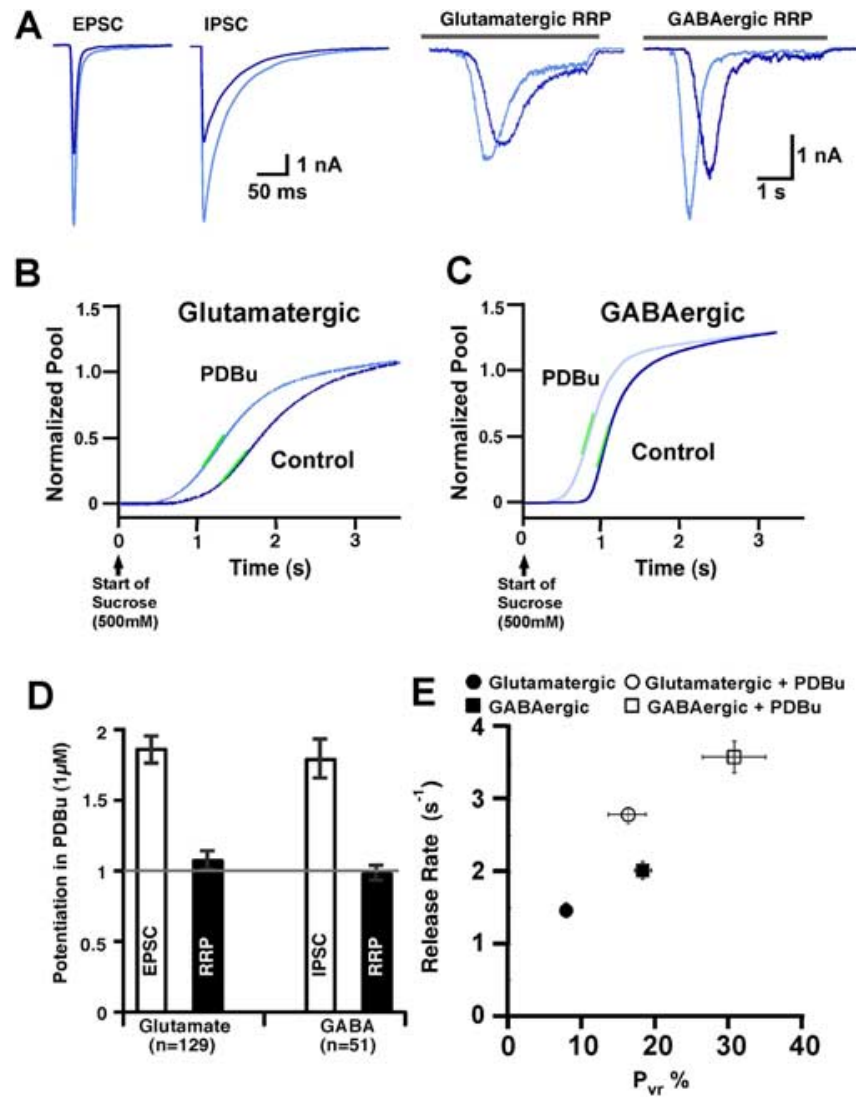

Figure 6. Comparison of release rates between glutamatergic and GABAergic hippocampal neurons. $A$, Typical raw traces of evoked (left) and $500 \mathrm{~mm}$ sucrose-induced (right) responses from wild-type glutamatergic and GABAergic neurons in the absence and presence of PDBu (1 $\mu \mathrm{M})$. Average normalized sucrose response integrals from excitatory $(\boldsymbol{B})$ and inhibitory $(\boldsymbol{C})$ neurons from control (dark blue) to PDBu-treated (light blue) conditions. Note the faster basal release kinetics in the inhibitory neurons. $E$, Bar plot of PSC potentiation and the lack of potentiation of RRP in glutamatergic $(n=129)$ and GABAergic $(n=51)$ hippocampal neurons. $\boldsymbol{E}$, Plot correlating the mean peak rate of vesicular release induced by $500 \mathrm{~mm}$ sucrose in hippocampal excitatory glutamatergic (circles) and inhibitory GABAergic (squares) autapses as a function of their average $P_{\mathrm{vr}}$ in their naive (filled symbols) and (1 domain-activated (open symbols) states.

changes in release during stimulation of the Munc13 C1 domain as glutamatergic neurons. Second, the intrinsically increased basal fusion rate and release probability seen in inhibitory cells is independent of $\mathrm{Ca}^{2+}$ influx, because the effect on evoked responses is paralleled by an increase in release rate for the sucrose response. This in turn implies that inhibitory vesicles have an intrinsically lower threshold of vesicular fusion, independent of Munc13 and the $\mathrm{Ca}^{2+}$-triggering step, but their regulation via $\mathrm{C} 1$ domain activation of Munc13s is similar to that of excitatory neurons.

\section{Discussion}

A major motivation for this study was to clarify the effect of $\mathrm{C} 1$ domain activation of Munc13s on vesicle priming and release probability. Although the mechanism of PDBu-induced presynaptic potentiation has been studied extensively, the strength of our approach is the ability to combine pharmacological (PDBu) and genetic (Munc13-1 ${ }^{\mathrm{H} 567 \mathrm{~K}}$ ) tools to interfere with $\mathrm{C} 1$ domain function of Munc13-1. Autaptic neurons uniquely allow simultaneous quantification of all forms of individual vesicular release. This study establishes that correlating different modes of release 
and analyzing their kinetics are useful methods to study putative alterations in vesicle fusion barrier.

Our main findings are that activation of the Munc13 C1 domain by PDBu potentiates the rate of spontaneously (increase of mEPSC frequency), hyperosmotically induced (faster response kinetics), or $\mathrm{Ca}^{2+}$-triggered (increased $\left.P_{\mathrm{vr}}\right)$ release, without altering RRP size. In addition to their role in priming, our study suggests that Munc13s are postpriming regulators of synaptic vesicle exocytosis. We also find that the PDBubinding-deficient Munc13-1 ${ }^{\mathrm{H} 567 \mathrm{~K}} \mathrm{C} 1$ domain mutant mimics the $\mathrm{C} 1$ domainactivated state, redefining it as a gain-offunction mutation.

\section{$\mathrm{PDBu}$ as a regulator of the energy \\ barrier for vesicle fusion}

The effect of phorbol esters on synaptic transmission has been extensively studied and usually lead to an increase in presynaptic release. The fact that Munc13s are vesicle-priming factors and major targets for DAG/PDBu-mediated modulation of synaptic release (Augustin et al., 1999; Rhee et al., 2002; Rosenmund et al., 2002) favors at first glance a mechanism through regulation of RRP size. In support, overexpression of Munc13-1 enhances neurotransmitter release at Xenopus neuromuscular junctions (Betz et al., 1998) and increases the exocytotic burst in chromaffin cells (Smith, 1999; Ashery et al., 2000; Stevens et al., 2005). We found that PDBu affects via Munc13-1 vesicular release rates on a timescale of seconds, without changing RRP size. Although this is strongly supported by independent pool measurements using $\mathrm{Ca}^{2+}$ uncaging in the calyx of Held (Lou et al., 2005), there are two other studies using essentially the same system and hypertonic solutionbased assay as our study, which suggest otherwise (Stevens and Sullivan, 1998; Virmani et al., 2005). As we discussed in Results, technical variability coupled with deviation from standard RRP definitions may account for these discrepancies. There may also be an effect of PDBu on presynaptic release and RRP size that depends on PKC. This component has, however, distinct kinetics, because it can be reliably revealed after $30 \mathrm{~min}$ preincubations with PKC inhibitors (Stevens and Sullivan, 1998; Capogna et al., 1999).

Our finding that activation of Munc13 C1 domain causes a left shift of the sensitivity to sucrose (Fig. $2 B$ ) indicates that activation of the $\mathrm{C} 1$ domain lowers the energy threshold for fusion of vesicles. More vesicles can be released with the same stimulus strength in case of low osmotic challenges, and all of the vesicles fuse more rapidly when faced with saturating concentrations of sucrose. This also implies that Munc13 C1 domain activation impacts vesicular release after vesicles have been primed to form the RRP, and hence Munc13s are not only priming proteins but also play a role as post-priming modulators of neurotransmitter release. In the calyx of Held preparation (Lou et al., 2005), PDBu potentiates evoked and spontaneous transmitter release by increasing the apparent $\mathrm{Ca}^{2+}$ sensitivity of vesicle fusion through allosteric regulation of fusion "willingness," possibly via a lowering of the energy barrier. High-frequency stimulation in hippocampal cultures increases exocytotic rates by a possible lowering of the barrier for vesicle fusion during augmentation (Stevens and Wesseling, 1999). Both of these findings are complementary to our study, in that they describe a potentiation of the release apparatus without changing RRP. Furthermore, we believe that these and our observations are describing the same fundamental process, involving a conformational change in the $\mathrm{N}$ terminus of Munc13s. In the case of augmentation, it includes among other likely processes the $\mathrm{Ca}^{2+}$ and activitydependent stimulation of N-terminal Munc13 domains by $\mathrm{Ca}^{2+}$ /calmodulin (Junge et al., 2004), and by DAG (Rhee et al., 2002; Rosenmund et al., 2002). 


\section{Molecular mechanism of $\mathrm{C} 1$ domain activation and Munc13 disinhibition}

Munc13s contain PKC-, Chimaerin-, and RasGRP-like "typical" DAG- and phorbol ester-binding C1 domains with two $\beta$-sheets, a short C-terminal $\alpha$-helix, and two $\mathrm{Zn}^{2+}$ binding sites (Hurley et al., 1997; Shen et al., 2005; Colon-Gonzalez and Kazanietz, 2006). Based on PKC models (Zhang et al., 1995; Xu et al., 1997) and $\beta 2$ Chimaerin structural data (Canagarajah et al., 2004), DAG receptors exist in a soluble inactive conformation in which the $\mathrm{C} 1$ domain hydrophobic ridge engages in intramolecular interactions. This sterically blocks the respective catalytic domain, directly or indirectly. Binding to phorbol esters or DAG break these inhibitory intramolecular interactions, thus activating the proteins. In their activated state, these proteins are deeply embedded into the membrane. Based on these allosteric activation models, we propose a mechanism of bimodal activity of Munc13s with two functional states (Fig. 7): a naive basal activity state in which the $\mathrm{C} 1$ domain binds to the Munc13 C terminus inhibiting the catalytic MUN domain, and an active potentiated state in which $\mathrm{PDBu} / \mathrm{DAG}$ binding to $\mathrm{C} 1$ domain disrupt intramolecular interactions and disinhibit the catalytic domain (Fig. 7). The basal folded configuration of Munc13 possibly favors the binding of C2A to RIM and formation of the priming-relevant tripartite complex. PDBu/DAG have been known to increase membrane association of $\mathrm{C} 1$ domains. Under conditions of increased DAG levels, e.g., during high-frequency activity, or after external application of $\mathrm{PDBu}, \mathrm{Cl}$ domain interactions with the membrane is favored, and this now competes with the intramolecular interactions of the protein, causing a conformational change that induces the activated state. In vivo, the other $\mathrm{Ca}^{2+}$-, calmodulin-, and phospholipid-targeted Munc13 N-terminal domains [C2B (J. S. Rhee, O. Shin, C. Rosenmund, N. Brose, T. Südhof, unpublished results); CaM (Junge et al., 2004)] may act in concert with the $\mathrm{C} 1$ domain to boost the catalytic activity of Munc13. Our model of disinhibition is strongly supported by the gain-offunction phenotype of the Munc13-1 ${ }^{\mathrm{H} 567 \mathrm{~K}} \mathrm{C} 1$ domain mutant. The histidine (H567) residue is a key residue in the $\mathrm{C} 1$ domain for chelating a central divalent $\mathrm{Zn}^{2+}$. We believe that the $\mathrm{H} 567 \mathrm{~K}$ mutation destroys the $\mathrm{Zn}^{2+}$-finger motif, not only preventing PDBu/DAG binding (Betz et al., 1998) but also interfering with the $\mathrm{C} 1$ domain-dependent intramolecular interactions. This leads to a constitutively disinhibited state of Munc13. Indeed, in the case of Chimaerins, the corresponding $\mathrm{C} 1$ domain mutation disrupts the $\mathrm{Zn}^{2+}$-finger motif and fully activates the Rac/Rho GTPase cascade (A. Betz and N. Brose, unpublished results). However, as a consequence of bypassing the basal conformation of Munc13, the KI mutant may have suffered interference with the N-terminal priming function.

\section{Functional implications of Munc13-1 as a post-priming regulator}

The dual mode of Munc13 function equips synapses with the ability to effectively regulate vesicular release probability. The basal autoinhibitory state may not only be useful in providing "reserve activity," but it also leads to lower spontaneous release activity, which in turn allows for a better discrimination of "noise" produced by spontaneous release as against evoked synaptic input to the postsynaptic neuron. The basal state of Munc13s may also help stabilize priming as such, as we discussed in our RRP data section, in that the gain-of-function Munc13$1^{\mathrm{H} 567 \mathrm{~K}}$ mutant might have interfered with $\mathrm{N}$-terminal priming functions.

In their activated state, Munc13s lower the energy barrier for vesicle fusion such that vesicles can be released at twofold to fourfold higher rates. When action potentials arrive at high frequencies, the higher $P_{\mathrm{vr}}$ will help to meet the higher demand for neurotransmitter release. During a step after priming, the catalytic MUN domain, once relieved of the hindrance from the $\mathrm{C} 1$ domain, may alter the state of the SNARE (soluble $N$-ethylmaleimide-sensitive factor attachment protein receptor) complex to regulate the rate and probability of vesicle fusion (Fig. 7 , activated state). There is evidence that Munc13 interacts directly (Betz et al., 1997; Sassa et al., 1999) or indirectly (Basu et al., 2005) with the regulatory N-terminal domain of the SNARE syntaxin-1. Syntaxin-1 can exist in an open and closed conformation, which regulates the state of assembly of the SNARE complex (Dulubova et al., 1999; Margittai et al., 2003). The conformational switch in syntaxin-1 is thought to involve Munc13 (Brose et al., 2000; Richmond et al., 2001). However, recent findings indicating that the open syntaxin can restore priming but not stimulus-evoked secretion in Unc13 mutants (McEwen et al., 2006) support the idea of an additional post-priming role of Munc13s. Similar to the functional properties of activated Munc13 synapses, syntaxin-1 open-form mutant synapses also show an increased $P_{\mathrm{vr}}$, accelerated release rates when stimulated with hypertonic solutions, and higher spontaneous release (S. Gerber, J. C. Rah, C. Rosenmund, and T. Südhof, unpublished data). This indicates that 'opening of Syntaxin 1' and 'opening of Munc13' have functionally equivalent impacts on the release machinery. Primed synaptic vesicles may possibly be equipped with SNARE complexes with variable fusogenic potentials depending on the associated Munc13 conformation. The energy barrier for fusion and ultimately the efficiency of spontaneous and $\mathrm{Ca}^{2+}$ triggered release are exponents of these different activity states taken together.

\section{References}

Andrews-Zwilling YS, Kawabe H, Reim K, Varoqueaux F, Brose N (2006) Binding to Rab3A-interacting molecule RIM regulates the presynaptic recruitment of Munc13-1 and ubMunc13-2. J Biol Chem 281:19720-19731.

Aravamudan B, Fergestad T, Davis WS, Rodesch CK, Broadie K (1999) Drosophila UNC-13 is essential for synaptic transmission. Nat Neurosci 2:965-971.

Ashery U, Varoqueaux F, Voets T, Betz A, Thakur P, Koch H, Neher E, Brose N, Rettig J (2000) Munc13-1 acts as a priming factor for large dense-core vesicles in bovine chromaffin cells. EMBO J 19:3586-3596.

Augustin I, Rosenmund C, Südhof TC, Brose N (1999) Munc13-1 is essential for fusion competence of glutamatergic synaptic vesicles. Nature 400:457-461.

Basu J, Shen N, Dulubova I, Lu J, Guan R, Guryev O, Grishin NV, Rosenmund C, Rizo J (2005) A minimal domain responsible for Munc13 activity. Nat Struct Mol Biol 12:1017-1018.

Betz A, Okamoto M, Benseler F, Brose N (1997) Direct interaction of the rat unc-13 homologue Munc13-1 with the $\mathrm{N}$ terminus of syntaxin. J Biol Chem 272:2520-2526.

Betz A, Ashery U, Rickmann M, Augustin I, Neher E, Südhof TC, Rettig J, Brose N (1998) Munc13-1 is a presynaptic phorbol ester receptor that enhances neurotransmitter release. Neuron 21:123-136.

Betz A, Thakur P, Junge HJ, Ashery U, Rhee JS, Scheuss V, Rosenmund C, Rettig J, Brose N (2001) Functional interaction of the active zone proteins Munc13-1 and RIM1 in synaptic vesicle priming. Neuron 30:183-196.

Brose N, Hoffman K, Hata Y, Sudhof TC (1995) Mammalian homologues of Caenorhabditis elegans unc-13 gene define novel family of C2-domain proteins. J Biol Chem 270:25273-25280.

Brose N, Rosenmund C, Rettig J (2000) Regulation of transmitter release by Unc-13 and its homologues. Curr Opin Neurobiol 10:303-311.

Canagarajah B, Leskow FC, Ho JY, Mischak H, Saidi LF, Kazanietz MG, Hurley JH (2004) Structural mechanism for lipid activation of the Racspecific GAP, beta2-chimaerin. Cell 119:407-418. 
Capogna M, Fankhauser C, Gagliardini V, Gahwiler BH, Thompson SM (1999) Excitatory synaptic transmission and its modulation by PKC is unchanged in the hippocampus of GAP-43-deficient mice. Eur J Neurosci 11:433-440.

Colon-Gonzalez F, Kazanietz MG (2006) C1 domains exposed: From diacylglycerol binding to protein-protein interactions. Biochim Biophys Acta 1761:827-837.

Dulubova I, Sugita S, Hill S, Hosaka M, Fernandez I, Sudhof T, Rizo J (1999) A conformational switch in syntaxin during exocytosis: role of Munc18. EMBO J 18:4372-4382.

Dulubova I, Lou X, Lu J, Huryeva I, Alam A, Schneggenburger R, Sudhof TC, Rizo J (2005) A Munc13/RIM/Rab3 tripartite complex: from priming to plasticity. EMBO J 24:2839-2850.

Hurley JH, Newton AC, Parker PJ, Blumberg PM, Nishizuka Y (1997) Taxonomy and function of $\mathrm{C} 1$ protein kinase $\mathrm{C}$ homology domains. Protein Sci 6:477-480.

Junge HJ, Rhee JS, Jahn O, Varoqueaux F, Spiess J, Waxham MN, Rosenmund C, Brose N (2004) Calmodulin and Munc13 form a $\mathrm{Ca}^{2+}$ sensor/effector complex that controls short-term synaptic plasticity. Cell 118:389-401.

Lou X, Scheuss V, Schneggenburger R (2005) Allosteric modulation of the presynaptic $\mathrm{Ca}^{2+}$ sensor for vesicle fusion. Nature 435:497-501.

Lu J, Machius M, Dulubova I, Dai H, Sudhof TC, Tomchick DR, Rizo J (2006) Structural basis for a Munc13-1 homodimer to Munc13-1/RIM heterodimer switch. PLoS Biol 4:e192.

Madison JM, Nurrish S, Kaplan JM (2005) UNC-13 interaction with syntaxin is required for synaptic transmission. Curr Biol 15:2236-2242.

Margittai M, Fasshauer D, Jahn R, Langen R (2003) The Habc domain and the SNARE core complex are connected by a highly flexible linker. Biochemistry 42:4009-4014.

McEwen JM, Madison JM, Dybbs M, Kaplan JM (2006) Antagonistic regulation of synaptic vesicle priming by Tomosyn and UNC-13. Neuron 51:303-315.

Pyott SJ, Rosenmund C (2002) The effects of temperature on vesicular supply and release in autaptic cultures of rat and mouse hippocampal neurons. J Physiol (Lond) 539:523-535.

Rhee J-S, Betz A, Pyott S, Reim K, Varoqueaux F, Augustin I, Hesse D, Südhof T, Takahashi M, Rosenmund C, Brose N (2002) b-Phorbol ester and diacylglycerol-induced augmentation of transmitter release is mediated by Munc13s and not by PKC. Cell 108:121-133.

Rhee JS, Li LY, Shin OH, Rah JC, Rizo J, Sudhof TC, Rosenmund C (2005) Augmenting neurotransmitter release by enhancing the apparent $\mathrm{Ca}^{2+}$ affinity of synaptotagmin 1. Proc Natl Acad Sci USA 102:18664-18669.

Richmond JE, Weimer RM, Jorgensen EM (2001) An open form of syntaxin bypasses the requirement for $\mathrm{UNC}-13$ in vesicle priming. Nature 412:338-341.

Rosenmund C, Stevens CF (1996) Definition of the readily releasable poo of vesicles at hippocampal synapses. Neuron 16:1197-1207.

Rosenmund C, Sigler A, Augustin I, Reim K, Brose B, Rhee J-S (2002) Differential control of vesicle priming and short-term plasticity by Munc13 isoforms. Neuron 33:411-425.

Sassa T, Harada S, Ogawa H, Rand JB, Maruyama IN, Hosono R (1999) Regulation of the UNC-18-Caenorhabditis elegans syntaxin complex by UNC-13. J Neurosci 19:4772-4777.

Shen N, Guryev O, Rizo J (2005) Intramolecular occlusion of the diacylglycerol-binding site in the $\mathrm{C} 1$ domain of munc13-1. Biochemistry 44:1089-1096.

Smith C (1999) A persistent activity-dependent facilitation in chromaffin cells is caused by $\mathrm{Ca}^{2+}$ activation of protein kinase C. J Neurosci 19:589-598.

Stevens CF, Sullivan JM (1998) Regulation of the readily releasable vesicle pool by protein kinase C. Neuron 21:885-893.

Stevens CF, Wesseling JF (1999) Augmentation is a potentiation of the exocytotic process. Neuron 22:139-146.

Stevens DR, Wu ZX, Matti U, Junge HJ, Schirra C, Becherer U, Wojcik SM, Brose N, Rettig J (2005) Identification of the minimal protein domain required for priming activity of Munc13-1. Curr Biol 15:2243-2248.

Varoqueaux F, Sigler A, Rhee JS, Brose N, Enk C, Reim K, Rosenmund C (2002) Total arrest of spontaneous and evoked synaptic transmission but normal synaptogenesis in the absence of Munc13-mediated vesicle priming. Proc Natl Acad Sci USA 99:9037-9042.

Virmani T, Ertunc M, Sara Y, Mozhayeva M, Kavalali ET (2005) Phorbol esters target the activity-dependent recycling pool and spare spontaneous vesicle recycling. J Neurosci 25:10922-10929.

Wojcik SM, Rhee JS, Herzog E, Sigler A, Jahn R, Takamori S, Brose N, Rosenmund C (2004) An essential role for vesicular glutamate transporter 1 (VGLUT1) in postnatal development and control of quantal size. Proc Natl Acad Sci USA 101:7158-7163.

Xu RX, Pawelczyk T, Xia TH, Brown SC (1997) NMR structure of a protein kinase C-gamma phorbol-binding domain and study of protein-lipid micelle interactions. Biochemistry 36:10709-10717.

Yawo H (1999) Protein kinase C potentiates transmitter release from the chick ciliary presynaptic terminal by increasing the exocytotic fusion probability. J Physiol (Lond) 515:169-180.

Zhang G, Kazanietz MG, Blumberg PM, Hurley JH (1995) Crystal structure of the cys 2 activator-binding domain of protein kinase $\mathrm{C}$ delta in complex with phorbol ester. Cell 81:917-924. 